\section{A Method for the Simultaneous Separation of Human Thrombocytes and Leucocytes}

\author{
D. NELKEN, N. GILBOA-GARBER, \\ AND J. GUREVITCH
}

From the Department of Clinical Microbiology, Hadassah University Hospital and the Hebrew University-Hadassah Medical School, Jerusalem, Israel

(RECEIVED FOR PUBLICATION DECEMBER 12, 1959)

The following method has been evolved from techniques described previously for the separation of thrombocytes (Gurevitch and Nelken, 1954) and leucocytes (Walford, Peterson, and Doyle, 1957). It has been tested on 200 various blood samples.

Only siliconized glassware was used. All centrifugations were carried out in a refrigerated centrifuge at $4^{\circ}$ C. A $1 \%$ solution each of $\mathrm{Na}_{2}$ sequestrene (disodium ethylene diamine tetra-acetic acid) and triton W.R. 1339 (oxyethylated tert. octyl phenol formaldehyde polymer) in $0.7 \%$ sodium chloride solution served as the anticoagulant.

Blood was withdrawn into a siliconized syringe containing anticoagulant in the proportion of $1: 9$ and divided into 5 aliquots of $20 \mathrm{ml}$. in $50 \mathrm{ml}$. roundbottomed centrifuge tubes. The blood was then centrifuged in a horizontal centrifuge at 800 r.p.m. $(110 \mathrm{~g})$ for seven minutes, causing the sedimentation of erythrocytes and leucocytes. The thrombocyterich plasma supernatant was drawn off and recentrifuged at 2,000 r.p.m. (600 g) for a further seven minutes. This second sediment contained the thrombocytes.

The thrombocyte-poor plasma supernatant was returned to the tube containing the erythrocytes and leucocytes and mixed well with the sedimented cells. To this "thrombocyte-poor blood" $\frac{1}{4}$ volume of a $6 \%$ dextran solution in physiological saline (intrinsic viscosity $0.40 / 20^{\circ}$ C.) was added. The dextran was

\section{A Rapid Method of Bleeding Mice (contd.)}

Hundreds of mice have been bled by this method in the determination of haemolytic titres to sheep red cells (Sobey and Adams, 1955; Sobey, Adams, and Claringbold, 1956; Claringbold, Sobey, and Adams, 1957) without mortality. Mice may be bled at the rate of one every one and a half minutes with an average yield of $0.25 \mathrm{ml}$. serum per bleeding.

\section{REFERENCES}

Bullen, J. J., and Batty, Irene (1956). J. Path. Bact., 71, 311. Bullen, J. J., and Batty, Irene (1956). J. Path. Bact., 71, 311.
Claringbold, P. J., Sobey, W. R., and Adams, K. M. (1957). Aust.
J. biol. Sci., 10, 367.

Sobey, W. R., and Adams, K. M. (1955). Ibid., 8, 603. first warmed to $37^{\circ} \mathrm{C}$. and mixed with the blood by transferring the dextran-blood mixture from one 50 $\mathrm{ml}$. siliconized tube to another. The mixture was allowed to stand at room temperature $\left(20^{\circ}-25^{\circ} \mathrm{C}\right.$.) for 30 minutes at an angle of $45^{\circ}$.

During this time sedimentation of the erythrocytes took place. The supernatant plasma containing the leucocytes, some erythrocytes, and few thrombocytes was centrifuged at 600 r.p.m. $(60 \mathrm{~g})$ for seven minutes. To the sediment thus obtained $6 \mathrm{ml}$. of distilled water was added to haemolyse the remaining erythrocytes and the tube shaken for exactly 25 seconds. Then $2 \mathrm{ml}$. of a $3.4 \% \mathrm{NaCl}$ solution was added in order to restore isotonicity. The tube was again centrifuged at 600 r.p.m. $(60 \mathrm{~g})$ for seven minutes. The haemolysed supernatant was removed, and the sediment contained the white blood cells.

The thrombocytes and leucocytes obtained in this manner could be diluted with normal saline as desired. The cells could be washed repeatedly in a washing fluid made of the standard anticoagulant solution diluted 1:10 with normal saline (unbuffered $p \mathrm{H} \mathrm{6-7)}$ without clumping. The average thrombocyte yield was $60 \%$. The contamination of the preparation by red blood cells was one erythrocyte to every 2,000 thrombocytes, and one leucocyte to 5,000-10,000 thrombocytes. The average leucocyte yield was $65 \%$ and the contamination by thrombocytes was 2-3 thrombocyte ghosts to every 100 leucocytes and 1-2 erythrocyte ghosts to 100 leucocytes. All counts were performed with the phase-contrast microscope.

The method described above did not present any difficulties, except in a few cases of leukaemia and in severe cases of polycythaemia. In the latter, the addition of $\frac{1}{5}$ volume of normal saline to the whole blood helped to improve the results. The rapid separation of thrombocytes and leucocytes, both of which are obtained in high yields, is a great advantage of this method. Furthermore, the cells appear morphologically intact, and have been used in immunological, metabolic, coagulation, and phagocytosis studies with good and reliable results.

This study has been assisted by a grant from the Leukaemia Research Foundation, Chicago, Ill., U.S.A.

\section{REFERENCES}

Gurevitch, J., and Nelken, D. (1954). Nature (Lond.), 173, 356. Walford, R. L., Peterson, E. T., and Doyle, P. (1957). Blood, 12, 953.

\section{First International Congress of Histochemistry and Cytochemistry}

The First International Congress of Histochemistry and Cytochemistry will be held in Paris from August 28 to September 3, 1960. 